\title{
Analysis on the Influence of Local Government Behavior on Regional Economic Development under the Current Fiscal System
}

\author{
Huang Juan, Jin Yong \\ Xijing University, Shaanxi Xi'an, China, 710123
}

Keywords: fiscal system; local government; regional development disparity of regional economic

Abstract: In the process of China's regional economic development, local governments, as the regulating body of regional economy, are the main body of protection. Some measures taken to prove their own interests will lead to unbalanced development of regional economy. This paper tries to analyze the existing problems, and the influence of local government's behavior on regional economic development under the financial system.

Development is a common topic faced by the countries in the world in the process of economic development. If this is the excessive imbalance will severely affect a country's economic and social development, even do serious harm for donational unity and political stability. The problem of regional economic development gap in China has existed for a long time.

Natural geographical factors, ideological factors, policy factors, layout and structure factors, capital issues, human capital and so on. Under the condition of market economy, the allocation of resources in the whole society should be based on market and regional economic development.

Exhibitions should also follow the basic laws of market economy, but the market is not omnipotent. In the development of regional economy, exhibitions should follow the basic laws of market economy. In some areas, the market is ineffective or inefficient. At this time, the local government is the main regulator of the regional economy. We need to give full play to our role and guide the harmonious development of regional economy.

\section{The role of local government in the development of regional economy}

\subsection{Market failure}

Market failure refers to the fact that the allocation of resources depends on the market mechanism and fails to achieve the optimal situation of Pareto.Under such circumstances, public goods can not be fully and equitable. Therefore, local government intervention is needed.To avoid overcoming market failure, however, the intervention and intervention of local governments in market activities can only be supplementary subsidized, not excessive intervention in power, violates the laws of market economy. 


\subsection{Localization of government interests}

Under the background of the widening regional disparity, local governments are driven by local interests or open to the public or local protectionism in the form of concealment. It has produced a series of actions that hinder the development of regional economy.The common obstacle facing the further expansion of each region is the division of administrative system, separated administration and administrative interregional relations. Instead of market interregional relations, it is difficult to optimize the allocation of resources.

\subsection{Lack of public services}

The government's public service refers to the production of the public sector based on the government, which is for the whole society to consume together.

The government's public service refers to the production of the public sector based on the government, which is for the whole society to consume together other public products and services. For a long time, local governments in China have provided public goods.

The following questions: Firstly, the investors of economic construction and public utilities are not balanced, and they are more productive and profitable.Infrastructure (transportation, hydropower, communications, etc.) and public affairs such as social security, culture and education, environmental protection, etc.Insufficient investment in the industry can hardly meet the requirements of economic and social development. Secondly, there is no investment in public utilities separating the managerial and non-managerial sectors has led to the continuous expansion of the public goods sector, which has caused a heavy financial burden.The shortage of financial expenditure limits not only the development of infrastructure, but also the development of public utilities. Thirdly, for a long while, some local governments have been pursuing growth unilaterally while ignoring the environment in the process of economic development.The protection has caused the incompatibility between human and natural environment.

\section{The influence of local government behavior on regional economic development under the fiscal tax sharing system.}

In 1994, China's fiscal and taxation system was reformed, and the tax sharing system was implemented. Government revenue has played an important role in mobilizing the enthusiasm of local development. Governments around the world are trying to develop local economy increases local fiscal revenue. However, the division of administrative regions is often inconsistent with economic regions. This pattern of development divides the market by administrative region, which inevitably leads to administrative interests and regional economic interests. The benefit subject conflicts in reality. Local governments at all levels, as the interests of the first class, seek the best interests of themselves. In the process of modernization, administrative means are often used to intervene directly in the economic operation, and excessive interference of administrative means leads to the "warlords'classic. The deviant behavior of local governments in regional economy has become a major factor hindering the development of regional economy.

The main effects are:

\subsection{The aggravation of local protectionism. Local governments have implemented their own interests in order to protect their interests.}

Party protectionism has greatly aggravated the difficulty of regional economic development. Local protectionism. There are various forms, which are mainly reflected in the administrative 
inconsistency between the local government's interregional factor flow and commodity trade.

Physical intervention. The concrete manifestation is that the local government does not make rational use of the market when the market capacity growth is limited. Political, economic and legal means to restrict the inflow of foreign products into local markets or to restrict resources, commodities, and the initial stage grade I products flow out of the local market; use economic policies to tilt, expanding the scope of management, increase approval procedures, and force the local authorities commercial enterprises operate, which acquires or promotes local products and is restrict enterprises in the region from transferring funds and technology to the region.In addition, they are directly involved in the field of capital transfer into economic management and law enforcement that many regions are in the interest of their own region.In the case of cross-regional disputes, for example, local governments are generally partial to enterprises in their own region.

These localistic actions, which run counter to the market economy, undermine the unity of the market and the fairness of competition. As a result, the economic structure is closed and the economic development deviates from the market direction, which ultimately limits the development of regional markets and aggravates them. The market separatism constitutes a great obstacle to the development of regional economic integration.

\subsection{Repeated construction is serious.}

With the prompting of local interests, all sectors of the country are developing industries with high profits and high profits. Textile industry, petrochemical, machinery, electronics, automobile and other high-input, high-output capital, technology-intensive industries. It leads to the serious phenomenon of repeated construction in various regions. Such blind local investment behavior results in regional industrial knot. The phenomena of convergence, uneconomical scale of enterprises, serious imbalance between processing capacity and the supply of energy and raw materials are wasted. It has provided resources, material resources and financial resources to foster the tendency of self-sufficiency in the establishment of a large, comprehensive, small and comprehensive local system.The industrial complementarity in regions is weak, and the industrial structure of the whole regional economy is in a low level of isomorphism. Economic development is inseparable from the strong support of the government. It also comes from the benefits of economic development, ending with economic development policy.The policy system formulated by the government and reasonable compliance helps. Standardizing local governments' support and promoting rapid regional economy development, and ultimately achieve the overall economic development of a country exhibition. After reform and opening up, China has established a market economy system. The country's economic system begins to shift from planned economy to market economy, so as to bring the market into full playing in the allocation of porcelain sources of moderating effect, under the function of market economy, the national economy of our country

Years of practice, it has been proved that the government has an important influence on the development of the economy, however, the sustained high speed of our economy in the past 30 years, growth is accompanied by social contradictions between cities and rural areas, the East and the west. There is the problem of regional disparity between the rich and the poor has been gradually expanding trend. Self regulation of market in regional economic development has also been an imbalance. It is inseparable from the behavior of the government. What is the intrinsic relationship between regional economy and government behavior? How does it affect the development of regional economy? regional economic development strategy .The economic development strategy is small to a large enterprise. The state is crucial to them whose the strategy is right.The impact of the organization's economic development is also very significant. So every organization has its own economic development. The strategy of development has certain functions 
for the government to formulate policies and policies. The macro guiding role is mainly manifested in two aspects.First, urban industrial priority development strategy. For China, at the beginning of its establishment, in order to get rid of poverty and make the national economy as fast as possible.With the development of economy, China has launched the priority development of heavy industry.After the economic strategy, China entered the industrial system. In the economic society, the national economy is developing slowly.In the past 30 years, more complete industrialization has been established economic system. It can be seen that the government's priority in the development of urban industry that is war. China has moved rapidly from backward agricultural countries to powerful industries system, which laid the foundation for the sustainable development of the economy foundation. However, the impact of economic development strategy is not only so, but also in the economic development. Behind the rapid development of industrialization, industrialization is also a priority development. Our country has brought huge regional economic gap between the rich and the poor. The labor and capital elements also flow to the economically developed areas.The area leads to technological backwardness, brain drain, and lack of investment.The problem has created a situation of unbalanced development. Second, export oriented development strategy. China has a vast territory. The economic disparity caused by regional characteristics is quite large. The southern coastal areas have close contacts with overseas countries, and their geographical advantages are obvious. The continuous influx of population and capital makes these areas cheap. Price labor and abundant economic resources. In reform and opening up. Initially, in the slogan of "getting rich first", the government moved to Haiti. The region has implemented an export oriented economic development strategy. On the basis of its regional advantages, sub regions actively respond to politics. Government policy vigorously develops foreign trade economy, concentrates on introducing everything else.The Ministry's resources and capital have kept our economy more than 30 years fast growth. And this export oriented regional economy has gain the most important achievement in the economic strategy is the introduction of developed countries abroad.The advanced technology and scientific management concept of the company.The long term economic development in coastal areas has been activated. But correspondingly,it is also the impact of the export oriented development strategy.There was a shortage of resources in the central and western parts of the country.A wealth of unbalanced phenomena, large amounts of capital, technology, talents, etc.The political and economic benefits of the members, so local governments and leaders often neglect to maximize their own interests.By looking at the overall interests, resulting in the inconsistency between the interests of local governments, local protectionism and local markets segmentation prevails. It must be based on local and overall interests, key tasks and overall work, short term goals and long term.Principle of combining far-reaching development and formulating comprehensive and scientific evaluation index and method of local government performance encourage measures and standardize the performance appraisal and promotion system of government officials as far as possible. Assessment of the government,in the direction of giving priority to comprehensive social benefits and supplementing economic growth indicators, we should not only examine the speed of economic growth more importantly, we should examine the quality of economic growth, and at the same time, we should take into account the local socio-economic development, its historical situation and long-term development.To develop organic integration, we should pay special attention to the ability of sustainable development of the region, and take the promotion of regional cooperation as an evaluation. The content of the local government's achievements, the introduction of social public evaluation standards, from people's satisfaction, quality of life, environmental standards Quasi-comprehensive evaluation of government management effectiveness is to form a set of scientific, normative and quantifiable cadre performance evaluation 


\section{Establish a standardized local public finance system.}

The local government's pursuit of local interests is concentrated on the maximization of fiscal revenue in local finance. The government has become an economic entity similar to the manufacturer. It is an important source that causes the serious disruption of the existing market operation relationship and the coordinated development of regional economy. To regulate the behavior of local governments and curb the short-term single act of local governments, we need to pay attention to the following points:

Define the functions of the government. The awareness of strengthening the government's public service is the government's effective implementation of the government's public services primary function. (2) arrange financial power with powers and powers, and determine the powers of the central government and local governments to prevent mutual interference vicious competition. (3) optimize the fiscal expenditure system. Through reasonable transfer payment, we should guide local governments to increase their associations. It will provide financial support for social, public and basic fields such as protection, technology, education and health. In addition, financial investment. We should gradually introduce the field of competition, only in this way can the competition of local governments enter a benign track.

\section{References}

[1] Gao Hongsen, regional economics (Second Edition) M. Beijing: Renmin University of China press, 2006:30-31

[2] Chen Xiushan, Xu Ying. An empirical study of the factors affecting China's regional disparity Study, 2004 (5)

[3] Li Dong Ke, Zhao Liu, the role of local government in regional development in Guizhou Polytechnic University Newspaper, 2006 (8): 6

[4] Wang Wenjian, Qin Cheng Lin's fiscal decentralization, local government behavior and regional economic growth based on Jing Testing and testing [economic theory and economic management, 2007 (10)] 